Pensares em Revista, ISSN 2317-2215

\title{
ENSINO DE LITERATURA: INTERFACES COM A CULTURA DIGITAL
}

\author{
Ivanda Maria Martins SILVA \\ (Universidade Federal Rural de Pernambuco) \\ martins.ivanda@gmail.com
}

\begin{abstract}
Resumo: $O$ turbilhão digital do ciberespaço vem influenciando as práticas de ensino-aprendizagem na escola. $O$ mundo dinâmico da cibercultura torna-se atrativo para os alunos que exploram os recursos das redes sociais, das múltiplas potencialidades da era multimídia, dos hipertextos, da convergência digital. Diante do contexto dinâmico das inovações tecnológicas, os professores precisam reavaliar sua condição de "imigrantes digitais" em contato com a geração dos "nativos digitais". (PRENSKY, 2001). No cenário da cultura digital, qual o papel reservado à literatura? Quais os desafios que os professores encontram para ensinar literatura diante do fascínio das inovações tecnológicas? Os professores estão sendo formados para ensinar literatura? Como analisar as relações entre os estudantes e a literatura em tempos de cultura digital? Esses questionamentos norteiam as reflexões apresentadas neste artigo, no sentido de contribuir para ampliar o debate sobre o ensino de literatura diante das inovações tecnológicas. O artigo aponta para a necessidade de se repensar a formação docente para o ensino de literatura, tendo em vista a importância do papel do professor de literatura como mediador das práticas de letramento literário dos estudantes.
\end{abstract}

Palavras-chave: Ensino de Literatura. Leitura. Cultura digital. Formação Docente.

\section{LITERATURE TEACHING: INTERFACES WITH DIGITAL CULTURE}

\begin{abstract}
The digital maelstrom of cyberspace is changing teaching and learning practices in the school. The dynamic world of cyberspace becomes attractive for students who explore the resources of social networks, the multiple potential of multimedia era, the hypertext, and the digital convergence. In the dynamic context of technological innovations, teachers need to reassess their condition of "digital immigrants" in touch with the "digital natives" (PRENSKY, 2001). In the present scenario of digital culture, what is the role of literature? Which are the challenges that teachers face to teach literature in face of the fascination exerted by technological innovations? Are the teachers being trained to teach literature? How ca the researcher analyze the relationship between students and literature in the age of digital culture? These questions rules the reflections presented in this article, in the way that it contributes to enlarge the debate about the teaching of literature regarding the technological innovations. Therefore, considering literature teaching, this article points to the necessity of rethinking the teacher training process, in the view of the importance of the literature teacher's role as mediator of learning in the students' literary literacy practices.
\end{abstract}

Keywords: Literature Teaching. Reading. Digital Culture. Teacher Training.

Pensares em Revista, São Gonçalo-RJ, n. 5, pág. 62 - 82, jul./dez. 2014

DOI: http://dx.doi.org/10.12957/pr.2014.16550 


\section{Considerações iniciais: educação no cenário da web 2.0}

Em tempos de web 2.0, as relações entre os sujeitos e os processos de ensino-aprendizagem estão sendo transformadas dentro e fora dos limites das salas de aulas. A revolução tecnológica tem provocado mudanças significativas no campo da educação. Computadores, celulares, TV digital, lousa digital, notebooks, tablets, e-books e vários outros recursos tecnológicos estão redimensionando a prática pedagógica dos professores.

Da tradição do giz e das salas de aula do ensino presencial, passa-se para o contexto da educação online (SANTOS, 2010), e os processos de ensinoaprendizagem revelam-se intensamente mediados pelas tecnologias digitais. A educação online vem consolidando seu papel na cibercultura (LÉVY, 1999), em que o acesso à informação torna-se bastante democrático.

Segundo Lévy (1999, p.17), a cibercultura envolve o "conjunto de técnicas (materiais e intelectuais), de práticas, de atitudes, de modos de pensamento e de valores que se desenvolvem juntamente com o crescimento do ciberespaço." Ainda nos termos de Lévy (1999), o mundo da cibercultura é marcado pela interatividade em que três princípios básicos orientam o crescimento do ciberespaço: a interconexão, a criação de comunidades virtuais e a inteligência coletiva. Nesse sentido, o ciberespaço funciona como novo meio de comunicação caracterizado não apenas pela infraestrutura material da comunicação digital, mas também pelo universo oceânico de informações disponibilizadas na web. (LÉVY, 1999).

$\mathrm{Na}$ cibercultura (LÉVY, 1999), vivemos os desafios da web $2.0 \mathrm{com}$ constantes inovações tecnológicas que despertam o interesse e a curiosidade dos estudantes. A web 2.0 vem se revelando como a nova geração da internet, caracterizada pelas rápidas trocas de informações e pela participação colaborativa dos internautas que compartilham suas experiências em blogs, vídeos do Youtube, Facebooks, enfim, uma infinidade de recursos que propiciam interações constantes no turbilhão digital do ciberespaço. (MATTAR, J.; VALENTE, 2007).

Alguns autores, como Stevens (2006) e Mason e Rennie (2008), citados por Demo (2009), apontam para a dinâmica social em rede, em que a web 2.0 facilita 
não apenas o acesso à informação, mas possibilita a interação com materiais, conteúdos, mídias, propiciando a noção de autoria coletiva.

No ciberespaço, as redes sociais estão se multiplicando rapidamente. As mudanças nas estratégias de relacionamento online criam novas redes que são constantemente atualizadas. Os internautas vão se inserindo nos espaços sociais das redes da web e estabelecem novas formas de comunicação/interação, compartilhando experiências com um número ilimitado de usuários.

Segundo Marteleto (2001, p.72), as redes sociais envolvem "[...] um conjunto de participantes autônomos, unindo ideias e recursos em torno de valores e interesses compartilhados". As redes sociais estabelecem relações de cooperação e compartilhamento de informações, por meio de uma "estrutura nãolinear, descentralizada, flexível, dinâmica, sem limites definidos e autoorganizável". (TOMÁEL, ALCARÁ e CHIARA, 2005). Essas redes podem ser utilizadas com diversas finalidades, tais como: divulgar e compartilhar experiências, promover maior interação entre os usuários, fornecer informações rapidamente, trocar ideias sobre livros e leituras preferidas, divulgar fotos, imagens, som e vídeos, além de diversos outros propósitos.

No cenário dinâmico da cibercultura, quais os desafios que os professores encontram para ensinar literatura, diante do fascínio das inovações tecnológicas? Os professores estão sendo formados para ensinar literatura? Como analisar as relações entre os estudantes e a literatura em tempos de cultura digital? Considerando tais questionamentos, o presente artigo visa contribuir para ampliar o debate sobre o ensino de literatura diante das inovações tecnológicas. Pretende-se refletir sobre o papel da literatura nesse contexto tecnológico, tendo em vista a formação docente para o ensino de literatura e a importância do professor como mediador das práticas de letramento literário dos estudantes.

\section{2 - Leitura, literatura e cultura digital: diálogos possíveis?}

Em tempos de cibercultura, comumente os professores deparam-se com o fascínio dos estudantes diante das ferramentas tecnológicas que invadem a escola e começam a competir com a própria organização tradicional das aulas de leitura e literatura. Tendo em vista enfoques ainda tradicionais de escolarização da leitura literária (SOARES,1999), observa-se a ausência de uma proposta de 
ensino interdisciplinar, fator que contribui para o estudo do texto literário como elemento isolado das demais disciplinas. Nessa escolarização inadequada (SOARES, 1999), o aluno não consegue interagir com o texto, pois o papel dinâmico do leitor é subestimado, sufocado pela leitura imposta pelo professor e pelos roteiros de interpretação dos manuais didáticos. Diante da imposição das leituras idealizadas pelos professores e pelos livros didáticos, constrói-se o mito de que a leitura literária é difícil, complexa e inacessível para os alunos, subestimando-se a capacidade interpretativa dos estudantes.

Buscando-se descontruir abordagens estigmatizadas em relação à leitura e à literatura na escola, não cabe mais o roteiro tradicional de ensino, em que as ações a seguir eram valorizadas: abrir o livro didático na página tal e ler o texto ali colocado; responder, por escrito, perguntas do questionário subsequente; fazer os exercícios gramaticais; escrever uma redação a partir do texto para a leitura e correção do professor. (SILVA, 1998). Esse modelo tornou-se anacrônico diante do dinamismo da cultura digital, em que as formas de ensinar e aprender são reconfiguradas para atender às demandas da sociedade tecnológica.

Os estudantes já não aprendem mais da mesma forma diante dos atrativos da cultura digital. Fascinados pelos celulares de última geração, com acesso a jogos, vídeos, fotos, redes sociais e notícias instantâneas, além dos deslumbramentos com os computadores mais modernos que cabem até na palma das mãos, crianças, jovens e adolescentes participam da cibercultura como "nativos digitais" (PRENSKY, 2001).

Enquanto o professor de literatura luta para chamar a atenção dos estudantes durante as aulas, os alunos navegam nas redes sociais, fotografam, filmam, registram selfies, enviam mensagens no WhatsApp, jogam games online, enfim, usam as tecnologias na própria sala de aula, sem finalidade didáticopedagógica, ou seja, um uso "escondido" da censura da escola, do olhar do professor, sem controle e sem propósitos definidos.

A leitura dos clássicos, como Shakespeare, Fernando Pessoa, Machado de Assis, Guimarães Rosa, Drummond, Clarice Lispector, Ariano Suassuna, e tantos outros, vai ficando cada vez mais distante, em função dos atrativos das telas dos celulares e tablets, da cultura de imagens, da interatividade das mídias digitais, das "amizades" ilimitadas nas redes sociais, das curtidas e compartilhamentos 
dos links, sites, enfim, as práticas de leitura vão se restringindo à superficialidade da rapidez das trocas interativas no ciberespaço.

O dinamismo das tecnologias digitais e a integração de mídias revolucionam as práticas de leitura, em função dos novos suportes tecnológicos. Os livros e as telas dialogam continuamente, provocando o fascínio dos jovens em relação a obras que são adaptadas para as telas dos cinemas, como Harry Potter, As Crônicas de Nárnia, A Saga Crepúsculo, O Senhor dos Anéis e outras.

Dos livros impressos às telas, mudam-se os suportes e transformam-se as relações entre os leitores, a leitura e a literatura. Com as inovações tecnológicas e transformações nos suportes, há uma nova importância dada aos efeitos produzidos no leitor e à construção do significado pelas diferenças estruturais entre o texto impresso e o texto virtual (CHARTIER, 1997). De que modo ocorre a interação entre texto e leitor, tendo em vista o surgimento de novas ferramentas interativas da comunicação eletrônica? Até que ponto a literatura mantém-se como um meio de conhecimento do homem e do mundo, se outros veículos de comunicação e de informação assumem espaços privilegiados? Qual será o papel reservado à literatura na era digital em que as "novas" tecnologias predominam e os leitores estão fascinados pela cultura de imagens?

Candido já comentava, na década de 70 , a função da literatura em contato com novas formas de comunicação. Conforme Candido (1972), os modernos meios de comunicação criaram alternativas para a necessidade humana de fantasia e de conhecimento simbólico da realidade. Nesse sentido, a literatura parece não ter mais o lugar privilegiado de antes, e isso traz repercussões para o ensino de literatura. Na perspectiva de Candido (1972), a necessidade de ficção manifesta-se a cada instante e a literatura funciona como resposta a essa necessidade universal, reconhecendo-se o texto ficcional em constante interação com os problemas sociais. Revela-se, assim, a função social da literatura que contribui para a formação do homem e começa a assumir novos rumos diante da concorrência com outros meios de comunicação.

Essa posição de Candido (1972) é retomada por vários críticos que discutem a situação da literatura a partir do advento das "novas" tecnologias. Iser (1998), por exemplo, levanta a seguinte questão: por que nós precisamos deste meio particular (a literatura), especialmente tendo em vista o fato de que a obra literária está competindo com outros meios que têm cada vez mais um papel 
crescente em nossa sociedade? Na perspectiva de Iser (1998, p.01), uma das características da literatura deve ser ressaltada como, por exemplo, a capacidade de ficcionalizar, construir mundos possíveis que dialogam com nossa realidade, seja transgredindo convenções, seja representando mimeticamente as relações sociais, culturais entre os indivíduos.

Cornis-Pope (2002, p.6) acredita não apenas nas facilidades trazidas pelas tecnologias, mas também num importante lugar que a literatura e as práticas de leitura literária estão assumindo rapidamente nesse contexto de revolução tecnológica. Nossa mais urgente tarefa é, segundo o autor, integrar a literatura num ambiente global, informacional, onde ela possa funcionar como um componente imaginativo integrado às práticas culturais.

Na perspectiva de Cornis-Pope (2002, p.3), por exemplo, as tecnologias eletrônicas permitem que os alunos leiam de modo multissequencial, com uma liberdade maior para testar suas habilidades interpretativas, examinando, construindo e reconstruindo suas leituras diante do texto literário virtual. A leitura de hipertextos também torna os leitores mais participativos na construção do sentido textual, uma vez que 0 ato de ler e 0 ato de escrever tornam-se inseparáveis. A crítica hipertextual estimula uma "autoria compartilhada", transformando leitores em leitores-autores ou "wreaders" (CORNIS-POPE, 2002), pois qualquer contribuição na web, criada por um leitor, é rapidamente avaliada e atualizada por outros leitores.

Com a internet, tanto a leitura, quanto as formas de comunicação escrita estão assumindo novas funções, ou seja, estamos aos poucos ajustando nossas estratégias comunicativas e interativas ao contexto dinâmico em que vivemos. Autores e leitores de obras literárias ajustam-se às novas estratégias de produção e recepção, estabelecendo contratos comunicativos que exigem um dinamismo maior. A leitura assume papel de destaque no contexto marcado pelo automatismo e pela superabundância de informações, ou seja, fatores que exigem um leitor ativo, extremamente dinâmico, capaz de selecionar quantitativa e qualitativamente informações.

Nesse contexto, é evidente o aumento na difusão da escrita e da leitura como atividades que sofrem alterações e se ajustam às novas exigências da cultura digital. Sem dúvida, estamos lendo e produzindo mais textos por conta das facilidades das ferramentas tecnológicas. Seja na leitura de homepages, na 
produção de e-mail, na seleção de informações ao navegar na rede, nas salas de bate-papos, nas conferências virtuais, ou em qualquer outra situação comunicativa desenvolvida no ciberespaço, o fato é que os indivíduos estão lendo e produzindo uma grande quantidade de textos. Mas o que estamos lendo e escrevendo após a revolução tecnológica? Quais as consequências das tecnologias da comunicação e da informação nas nossas práticas de leitura e escrita? Qual a qualidade do material lido pelos leitores-navegadores?

Ao investigar as transformações em nossas práticas de leitura, após a internet, argumenta Silva (1998, p.15):

Aos suportes impressos somaram-se os suportes eletrônicos da comunicação, fazendo crescer excepcionalmente a circulação da escrita nas sociedades letradas. Com esse crescimento e frente à verdadeira avalanche cotidiana de materiais escritos, o julgamento sobre a qualidade desses materiais, orientando os processos de seleção para o uso objetivo do tempo, impõe-se como uma necessidade concreta e irrefutável.

Como podemos notar, o julgamento sobre a qualidade do material lido torna-se pré-requisito para o leitor crítico, isto é, aquele capaz de estabelecer uma relação entre a leitura crítica do mundo e a leitura da palavra escrita. Freire (1995, p.11) afirma que "a leitura crítica do mundo precede a leitura da palavra, pois linguagem e realidade se ligam dinamicamente". Na perspectiva do autor: "a compreensão do texto a ser alcançada por sua leitura crítica implica a percepção das relações entre o texto lido e o contexto". (FREIRE, 1995, p.11).

O mundo é um grande texto, na visão de Freire (1995), e precisa ser decifrado pelo leitor crítico. É justamente no diálogo entre a leitura do mundo e a leitura da palavra que se revela o leitor crítico, aquele capaz de analisar a realidade social a partir do caráter dinâmico da leitura, em que autor-texto-leitormundo são elementos estreitamente ligados.

O desenvolvimento de leitores críticos, capazes de selecionar e armazenar informações, torna-se fundamental num mundo marcado pela massificação cultural. Muitos leitores desempenham um papel de passividade diante do dinamismo das ferramentas tecnológicas, não conseguem selecionar qualitativamente informações e realizam uma recepção mecânica dos meios eletrônicos. Essa passividade é observada quando os alunos não utilizam a tecnologia de modo crítico-reflexivo e autoral, praticando o ato de "copiar e colar" sem medir as consequências, apropriando-se do discurso do outro sem considerar as normas de citação da ABNT, por exemplo. 
Atônitos diante do turbilhão digital da internet, os alunos perdem-se nas pesquisas escolares, navegam de forma superficial pelos resumos das obras clássicas da literatura, realizam práticas de leitura sem propósitos definidos, não conseguem, pois, compreender o poder ilimitado do ciberespaço no acesso a acervos de bibliotecas virtuais. Se antes o acesso ao livro era mais difícil, hoje, com a internet, a democratização da leitura revela-se importante para os leitores buscarem obras esgotadas, navegando em sebos virtuais, sites de bibliotecas literárias, portais de domínio público com acervos de obras clássicas, enfim, o encontro entre a literatura e os leitores tornou-se mais acessível.

No entanto, em lugar de aproximarem-se das grandes obras literárias, ampliando suas práticas de letramento literário (COSSON, 2006), agora com o acervo digital disponível no ciberespaço, os jovens estudantes, na maior parte das vezes, navegam sem direção no oceano de informações da web. $O$ acesso dos estudantes à internet parece limitar-se ao Facebook, ao Twitter, aos vídeos do YouTube, aos jogos digitais, além de outras ferramentas do ciberespaço que começam a concorrer com o tempo dos estudos, das leituras, das tarefas e das pesquisas escolares.

Na perspectiva de Eco (2000, p.11), "a internet é como uma enchente, não há como parar a invasão de informação". Segundo o autor, um aspecto negativo da internet é a abundância de informação; uma boa quantidade de informação é benéfica e 0 excesso pode ser péssimo, porque não se consegue selecionar qualitativamente as informações. Nessa "enchente de informações" e diante dos atrativos do universo digital, a literatura busca meios de conquistar os leitores, cada vez mais entusiasmados com as mídias digitais e com a cultura de massa.

Na ótica de Perrone-Moisés (1998, p.206), os valores estético-literários são progressivamente vencidos por uma "cultura de massa embrutecedora, ou transformados em mercadoria de grife na indústria cultural". Ainda na perspectiva da autora, a superabundância e a rapidez das informações na situação atual não permitem ao leitor nenhuma seleção real, comprometendo a visão crítica dos consumidores que se deparam com a efemeridade das informações virtuais e 0 crescente processo de massificação cultural. (PERRONE-MOISÉS, 1998, p.204).

O que diz Perrone-Moisés (1998) sobre a situação da literatura aplica-se ao espaço de sala de aula, onde observamos a falta de interesse dos alunos pela leitura literária e a valorização da biografia dos autores, como se esta pudesse 
explicar a própria obra ficcional. Grande parte dos professores ainda cultiva a concepção do texto como pretexto para se estudar a vida do autor, buscando explicar a obra literária por meio de conhecimentos de dados biográficos.

Diante da massificação do fato literário, Benjamin (1985) denuncia a perda da aura das obras artísticas. Para Benjamin, a essência da arte de narrar é posta em cheque quando, modernamente, nossas experiências deixam de ser comunicáveis. Conforme o autor, "a arte de narrar está definhando porque a sabedoria - o lado épico da verdade - está em extinção". (BENJAMIN, 1985, p.200-202).

Analisando a crise da modernidade e suas relações com a prática pedagógica, Kramer (1993, p.53) discute, à luz do enfoque de Benjamin (1985), como essa crise da arte de narrar pode interferir no contexto escolar:

\footnotetext{
Não terá esse 'definhamento da arte de narrar' ou essa 'extinção da sabedoria (o lado épico da verdade)' profundas consequências sobre a educação, a escola e o trabalho do professor, na medida em que com a narrativa em extinção parece definhar o próprio sentido de educar, ensinar, aprender? Quem narra hoje na escola? O professor? O aluno? Ou ninguém? (KRAMER, 1993, p.53).
}

Nessas circunstâncias em que a troca de experiências narrativas está definhando diante, por exemplo, de formas atrativas de comunicação como as redes sociais, os bate-papos virtuais, os e-mails e tantas outras, parece-nos que o aluno dedica-se cada vez menos à leitura literária, sem que a escola consiga atraí-lo para que desenvolva de forma qualitativa e também quantitativa o ato da leitura.

Num contexto em que a informação é disputada por todos, a partir de meios de comunicação diversos, a experiência de vida e de leituras, isto é, o repertório dos leitores torna-se elemento central na discussão sobre a capacidade de selecionar textos que contribuam para o desenvolvimento da leitura enquanto atividade dinâmica de transformação e não de acomodação.

Acreditamos que não cabe à literatura competir com os meios modernos de comunicação que surgiram com o desenvolvimento das inovações tecnológicas. Certamente, como meio de expressão das relações sociais, políticas, históricas e culturais, a literatura sempre terá seu lugar garantido numa sociedade em que a informação ganha destaque e o conhecimento global torna-se pré-requisito para os profissionais do futuro. 
$O$ ato de ler, com o propósito da busca da informação e do conhecimento, não irá destruir ou restringir as práticas de leitura voltadas para o prazer estético do texto literário. A leitura literária certamente pode contribuir para a compreensão crítica do mundo, visto que a obra de ficção constrói um mundo possível que dialoga com nossa realidade. A função lúdica, imaginativa e criativa que a literatura desempenha não perderá espaço diante de outros meios atrativos de comunicação que prendem a atenção do receptor por meio do privilégio da iconicidade.

Como afirma Melo (BARZOTTO, 1999, p.67):

O surgimento de novos meios acarreta mudanças na estrutura de produção, determinando alterações na política comunicacional dos já existentes, mas não elimina o seu uso. Cada meio passa a ter um espaço definido de atuação atendendo a expectativas e necessidades específicas do público consumidor.

No cenário dinâmico das inovações tecnológicas, a literatura busca adaptar-se e encontra novos caminhos, seja nas transformações dos gêneros literários diante dos novos suportes, seja nas relações entre autores-textosleitores agora mediadas pelas mídias digitais. Leitores e autores deparam-se com hiperfiç̧ão, ciberpoemas, fotopoesia, poesia digital, fanfics, blogs literários, além de uma série de novos espaços hipermidiáticos e discursivos para práticas de letramento literário.

Portanto, a literatura terá seu espaço garantido e assumirá papéis diferentes a partir da interação com os modernos meios de comunicação, mas a função social da obra literária e a capacidade de ficcionalização, assinaladas por Iser (1998), sempre serão fatores que contribuirão para a permanência desse objeto artístico capaz de transformar o leitor a cada nova leitura. No entanto, autores e leitores devem repensar seus papéis em face do texto literário. Nessa era digital, não poderemos continuar com uma postura tradicional diante da literatura. Os professores também devem reavaliar sua prática pedagógica quando inserirem o texto literário no contexto de sala de aula.

Acreditamos que o futuro da literatura está intimamente relacionado à forma de se encarar a obra literária, que deve ser considerada como um meio de conhecer melhor o mundo e nós mesmos, enquanto leitores, promovendo-se uma articulação entre a leitura crítica do mundo e a leitura do texto literário. É preciso que os leitores descubram o mundo contido nos textos literários como um espaço 
para experienciar sentimentos, atitudes e posturas vivenciadas por personagens, que traduzem expectativas nossas diante da própria realidade.

No universo atrativo das telas dos computadores, em que chats, homepages, visitas ilimitadas aos sites, downloads, blogs e e-mails ganham destaque, a leitura literária pode ficar confinada a um grupo restrito de leitores, se o objeto literário não for atualizado de forma interativa e dinâmica. Os leitores devem encarar a obra como objeto de prazer estético, emocional e intelectual, usando-a para satisfazer suas necessidades. Nesse sentido, a obra torna-se para o leitor um meio de conhecimento, de diversão, uma forma de buscar sua identidade, influenciando sua própria vida.

Concordamos com Iser (1998), quando afirma que se um texto literário faz algo com seus leitores, ele também simultaneamente nos conta algo sobre esses leitores. Então, a literatura nos leva a um mergulho em direção a nossas disposições, desejos, inclinações e eventualmente a nossa complexidade global. A nosso ver, a leitura literária será sempre um jogo de descobertas e negociações de sentidos, em que nós, leitores, buscamos encontrar no texto a chave para entender as regras do jogo.

Considerando a influência das inovações tecnológicas e as características da cultura digital, como professores, estamos preparados para ensinar literatura? De que modo a formação docente para o ensino de literatura está acompanhando as transformações tecnológicas? Certamente esses questionamentos tornam-se relevantes quando refletimos sobre o ensino de literatura na cultura digital, como veremos na próxima seção.

\section{3 - Formação docente para ensino de literatura na cultura digital}

Nas discussões sobre o ensino de literatura, a figura do professor é quase sempre ressaltada, compreendendo-se o educador como principal responsável pela formação de leitores críticos. Se o aluno não aprende, se o aluno não está motivado para aprender, se o aluno não gosta de ler, se o aluno detesta literatura, quase sempre, diferentes vozes ecoam responsabilizando apenas o professor. $\mathrm{Na}$ maior parte das vezes, a direção da escola, a coordenação pedagógica, os pais, e os próprios alunos unem-se em uma espécie de "orquestração polifônica" (BAKHTIN, 1993), direcionando a responsabilidade do ensino de literatura única e 
exclusivamente para 0 professor. Mas, não seria importante considerar 0 processo de formação docente como fator relevante nessa discussão? Ou seja, os professores de literatura estão sendo formados para ensinar literatura?

Nesse debate, acreditamos que o professor de literatura depara-se com os desafios de uma precária formação docente nos cursos de licenciaturas, nos quais a literatura parece não ocupar espaço tão privilegiado no currículo. Como exemplos, os cursos de Licenciatura em Letras visam formar docentes para o ensino de língua portuguesa e literatura, no entanto, os currículos ainda parecem desconsiderar a importância da literatura nesse processo de formação.

Os currículos dos cursos de Licenciatura em Letras revelam ainda uma perspectiva dicotômica, quando apresentam, de um lado, estudos linguísticos, e de outro, estudos literários, sem interconexões dialógicas. Os licenciandos são habilitados para ensinar língua portuguesa e literatura, entretanto, uma vez formados, sob uma ótica disciplinar e fragmentada do currículo, especializam-se como professores de língua portuguesa ou de literatura.

No currículo da educação básica, a carga horária destinada às aulas de língua portuguesa é bem superior àquela para as aulas de literatura, o que certamente torna-se fator decisivo quando o docente precisa optar pelo ensino de língua ou literatura. Desse modo, seja no currículo das universidades, seja na matriz curricular da educação básica, o fato é que a literatura parece estar sempre em desvantagem, se considerarmos a carga horária ainda limitada para a diversidade de conteúdos. Também nos vestibulares e exames, como o ENEM, por exemplo, a literatura ocupa espaço ainda tímido, com poucas questões, se compararmos com a quantidade maior de questões para língua portuguesa.

Somando-se a esses aspectos, as lacunas na formação inicial docente em relação às metodologias e práticas pedagógicas parecem conduzir os professores para uma ação docente em que se aprende a "dar aulas dando aulas". Nesse sentido, a própria prática docente torna-se principal instrumento de trabalho do professor que, muitas vezes, não consegue visualizar as articulações entre seu processo de formação inicial e as constantes demandas da sala de aula.

Freitas (2009) tem estudado nos últimos anos os processos de formação docente no contexto da cibercultura. Fazendo uma síntese dos achados de suas pesquisas, a autora afirma que: 
em relação à formação inicial de professores, pudemos compreender como os professores desses cursos de formação, tanto presenciais quanto a distância, ainda não se integraram de fato à cibercultura. Até fazem certo uso pessoal do computador e acessam a internet para comunicação através de e-mail e alguma navegação pela web; no entanto, não vinculam essas atividades à sua prática pedagógica. (FREITAS, 2009, p.67).

Na condição de "imigrantes digitais" (PRENSKY, 2001), os professores precisam aprimorar suas práticas de letramento digital (COSCARELLI, C. V; RIBEIRO, 2005), no sentido de reinventarem sua ação docente na cibercultura, buscando motivar os estudantes (nativos digitais) para o ensino de literatura articulado aos desafios da web 2.0. Mas, como integrar a prática docente à cibercultura, se os cursos de formação inicial não preparam de modo satisfatório os professores?

$\mathrm{Na}$ maior parte das vezes, os educadores iniciam seus percursos na docência e se deparam com os constantes desafios da educação básica, ou seja, baixos salários, alunos não leitores, desmotivação dos discentes para os processos de ensino-aprendizagem, escassez de recursos e materiais didáticos, entre outros. Como, então, ensinar literatura se o professor não foi formado para o ensino da literatura? Como ensinar literatura para alunos não leitores? Como ensinar literatura se o potencial de ficcionalização está sendo reconfigurado para outras mídias e tecnologias? Como ensinar literatura em tempos de e-books e ereaders?

Questões começam a surgir diante das mudanças de paradigmas na cultura digital, em que autores e leitores estão redimensionando seus papéis e começam a estabelecer novas relações com os livros. Nesse contexto, as próprias reflexões sobre o ensino de literatura e o papel dos docentes revelam-se mais evidentes. Será que é possível ensinar literatura em tempos de cultura digital?

Alguns autores defendem a tese de que o ensino de literatura precisa ser debatido, considerando-se 0 ato da experiência estética como ação individualizada e variável de leitor a leitor. Nesse sentido, defendendo a necessidade de o leitor experienciar a obra literária, Matos (1987) afirma: "o ensino da literatura é, em rigor, impossível, pela simples razão de que a experiência não se ensina. Faz-se. Mas podem e devem criar-se as condições para essa experiência: removendo obstáculos e proporcionando ocasiões." (MATOS, 1987, p.20). 
É também o ponto de vista de Fish (1986) quando defende que ler não é um exercício de deduzir ou decodificar o sentido da mensagem, mas sim o processo de vivenciar o texto. É a partir da experiência estética que o sentido se constrói e se revela na interação texto-leitor.

A experiência da literatura, conforme Hester (1972, p. 284), raramente ocorre em sala de aula. Segundo o autor, podemos preparar nossos alunos para experienciar um texto literário e devemos intensificar essa atividade. No entanto, não estamos plenamente aptos a produzir essa experiência como uma realidade mútua para nós e outros leitores. Em outros termos, a experiência da leitura literária é de natureza individual, varia de leitor a leitor e deve ocorrer de forma natural, considerando a privacidade do leitor em sua relação com o objeto literário.

A questão que se coloca é se essa experiência estética está sendo proporcionada aos alunos dentro e fora dos limites das salas de aula. De que modo os alunos estão estabelecendo interações com a literatura, seja no processo de escolarização da leitura literária, comumente evidenciado dentro dos muros da escola, seja nos espaços ilimitados do turbilhão digital, dos universos oceânicos de informações da internet? De uma forma ou de outra, certamente o professor tem papel capital como mediador das interações entre os estudantes leitores e as obras literárias. Esse papel do docente merece ser valorizado, compreendendo-se a importância do professor de literatura como agente de transformação das práticas de letramento literário de seus estudantes.

Os programas de formação inicial e continuada dos docentes merecem ser redimensionados, considerando-se os desafios que os professores estão enfrentando em tempos de cultura digital. É preciso formar professores leitores, sujeitos com autonomia nas práticas de letramento literário, visto que serão responsáveis por disseminar a cultura literária junto aos estudantes da educação básica.

A educação literária proposta pela escola precisa ser reavaliada, a fim de que nossos estudantes possam encontrar razões concretas para o estudo da literatura como fenômeno artístico atrelado às transformações históricas, sociais e culturais (SILVA, 2005). Nesse processo, o professor precisa rever sua prática pedagógica, apropriando-se das questões teórico-metodológicas sobre ensino de 
literatura, bem como considerando as relações que os estudantes estão estabelecendo com a literatura nesse cenário de inovações tecnológicas.

Não cabe mais o ensino tradicional da história da literatura, principalmente como se nota no ensino médio, com a ênfase na classificação de autores e obras em períodos literários isolados e descontextualizados. Retomando as considerações de Leahy-Dios (2001), de que adianta "ensinar" os alunos a memorizar características dos diferentes estilos de época, situando-se a produção literária em "blocos monolíticos de períodos literários", se os educandos não conseguem ter uma compreensão mais ampla do objeto literário?

Concordamos com Lopes (1994, p.368): "ensinar literatura não pode deixar de ter em conta esta dupla dimensão dos textos literários pela qual, ao mesmo tempo que fazem parte da cultura, e por conseguinte do campo da opinião ou das significações consensuais, são sobretudo o abalar destas." Assim, ensinar literatura não é apenas elencar uma série de textos ou autores e classificá-los num determinado período literário, mas sim revelar para o aluno o caráter atemporal, bem como a função simbólica e social da obra literária.

Retomamos aqui as considerações de Beach e Marshall (1991, p.17): "o estudo da literatura poderia ser justificado por sua habilidade para ajudar os alunos a compreenderem a si próprios, sua comunidade e seu mundo mais profundamente". É essa integração entre a literatura e o contexto sociocultural que a escola deve proporcionar aos alunos, levando-os a perceber as possibilidades de significação que o texto literário permite, enquanto objeto artístico polissêmico que transgride normas e regras, envolvendo o leitor num jogo de construção e reconstrução de sentidos.

No entanto, a tarefa de colocar o aluno diante da obra literária - objeto lúdico de construção e negociação de sentidos - ainda constitui um desafio no contexto escolar. Conforme Kramsch (JACOBUS, 1996, p.134), os alunos precisam entender o texto literário como uma forma de (re)descoberta de sua própria identidade, por meio da reescrita que se concretiza no ato de ler, momento em que o leitor responde ativamente ao texto. Segundo Edmonds e Skerrett (In: JACOBUS, 1996, p.140), o professor pode usar a literatura como um meio de os alunos interpretarem a si próprios.

Rosenblatt (JACOBUS, 1996, p.141) afirma que a obra literária oferece uma oportunidade de o leitor se envolver numa experiência de reconstrução dos 
acontecimentos vividos pelas personagens. Enquanto alguns críticos acreditam que é perigoso deixar o texto à mercê simplesmente da concentração exclusiva das opiniões pessoais dos alunos, Rosenblatt (JACOBUS, 1996) argumenta que precisamos ajudar os alunos-leitores a desenvolverem uma leitura estética da obra. Os professores deveriam encorajar os alunos, para que estes desenvolvam suas próprias experiências no ato da leitura. O papel do professor precisa ser crítico-reflexivo ao selecionar obras que permitam uma interação mais produtiva, além de utilizar questões que possam deixar clara a relação entre a experiência do aluno e o texto.

\section{4 - Navegando rumo às conexões finais}

Diante dos avanços das tecnologias da informação e comunicação, a escola precisa reavaliar o papel da literatura dentro e fora da sala de aula, a fim de estreitar as relações entre os alunos e a leitura literária. O futuro da literatura será garantido pela capacidade de ficcionalização, como propôs Iser (1998), pois o homem sempre precisará de meios capazes de representar seus anseios, desejos, sonhos, enfim, algo que mantenha sua imaginação sempre viva e ativa.

A escola parece ainda não ter conseguido se adaptar às exigências do mundo moderno, no que se refere ao tratamento dado à literatura. Esta ainda é trabalhada, de modo geral, como objeto autônomo, distante das interferências criativas dos alunos leitores, visto que são priorizadas análises tradicionais que desmotivam a leitura por prazer e enfatizam a leitura como uma forma de obrigação, sempre atrelada aos exercícios escolares.

É importante valorizar o trabalho docente no processo de mediação entre autores, obras e leitores, considerando os constantes desafios da cultura digital, bem como é essencial reavaliar metodologias e práticas docentes direcionadas ao ensino de literatura nesse cenário de inovações tecnológicas.

Alguns questionamentos podem ser importantes para nós, professores(as). Nesse sentido, comecemos a refletir: Como professores de língua e de literatura, estamos conseguindo motivar nossos alunos à leitura, principalmente à leitura literária? Quais as possíveis estratégias que poderemos desenvolver para que o aluno reconheça a função sociocultural da literatura? Estamos usando a literatura como pretexto para o ensino-aprendizagem de questões puramente gramaticais 
e estilísticas? De que modo utilizamos o livro didático em sala de aula? De que forma estamos integrando o ensino de literatura à cultura digital?

Pensar nesses questionamentos já é um grande passo para reavaliarmos nossa ação docente, com vistas à ampliação das práticas de letramento literário dos estudantes. Certamente não há "roteiros ou receitas prontas" para se trabalhar a literatura dentro ou fora dos limites da sala de aula. A sala de aula agora é também virtual, e estará sempre aberta à curiosidade dos estudantes, ao encantamento dos leitores, às paragens literárias, às múltiplas faces das palavras. Como diria Drummond (2012):

Chega mais perto e contempla as palavras.

Cada uma

tem mil faces secretas sob a face neutra e te pergunta, sem interesse pela resposta, pobre ou terrível, que the deres:

Trouxeste a chave?

É importante que o professor ensine literatura, fazendo com que o aluno perceba as "mil faces secretas das palavras", articulando o dito ao não dito, conhecendo a polissemia das obras literárias. Cada professor irá encontrar o seu caminho, identificando as principais dificuldades de seus alunos na recepção do texto literário e buscando encontrar alternativas para minimizar a desmotivação dos educandos diante do ato de ler.

Como afirma Cereja (2005), é preciso que o ensino de literatura seja articulado a uma abordagem dialógica, capaz de promover encontros entre autores, leitores, textos, linguagens, contextos. Nessa perspectiva dialógica, o ensino de literatura deve acompanhar as transformações da cultura digital, e o professor precisa criar situações didáticas para que os estudantes experienciem a obra literária, seja folheando um livro em meio impresso, seja navegando nas telas dos computadores, tablets e celulares de última geração. 


\section{Referências bibliográficas}

BAKHTIN, M. Questões de Literatura e de estética: a teoria do romance. São Paulo: Unesp, 1993.

BARZOTTO, V. H. (Org.) Estado de leitura. Campinas: Mercado de Letras, 1999.

BENJAMIN, W. Magia e técnica, arte e política: ensaios sobre Literatura e História da Cultura. São Paulo: Brasiliense, 1985.

BEACH, R. W.; MARSHAI, J. P. Teaching literature in the secondary school. Orlando: Harcourt Brace \& Company, 1991.

BORDINI, M., AGUIAR, V. Literatura: a formação do leitor. Porto Alegre: Mercado Aberto, 1993.

CANDIDO, A. A literatura e a formação do homem. Revista de Ciência e Cultura. v.24, set. 1972.

CEREJA, W. R. Ensino de Literatura: uma abordagem dialógica para o trabalho com a literatura. São Paulo: Atual, 2005.

CHARTIER, R. (Org.) Práticas da leitura. São Paulo: Estação Liberdade, 1996.

. Chartier interview: an interview with Roger Chartier. Sharp News. v.6, n.2, p.01-09, 1997.

A aventura do livro: do leitor ao navegador. São Paulo : UNESP, 1999.

CORNIS-POPE, M. Literary education in the age of hypertextual and networked communication: strategies for an interactive critical pedagogy. Disponível em: <http://www. liternet.revolta.com/iser/poper1.htm > Acesso em: 25 out. 2002.

COSCARELLI, C. V; RIBEIRO (Orgs.). Letramento Digital: aspectos sociais e possiblidades pedadógicas. Belo Horizonte: Autêntica. 2005.

COSSON, R. Letramento literário: teoria e prática. São Paulo: Contexto, 2006.

COSTA, R. Por um novo conceito de comunidade: redes sociais, comunidades pessoais, inteligência coletiva. Interface (Botucatu) [online]. 2005, vol.9, n.17, pp. 235-248.

DEMO, P. Educação hoje: "novas" tecnologias, pressões e oportunidades. São Paulo: Atlas, 2009.

DRUMMOND, C. A rosa do povo. São Paulo: Companhia das Letras, 2012.

ECO, U. Leitura do texto literário. Lector in fabula: a cooperação interpretativa nos textos literários. Lisboa : Presença, 1993. 
. "O dilúvio da informação". Veja vida digital. n.04. p.11-15, dez. 2000.

EVANGELISTA, A; BRANDÃO, H. (Orgs.). A escolarização da leitura literária. Belo Horizonte: Autêntica, 1999.

FISH, S. Literature in the reader: affective stylistics. In: TOMPKINS, J. (Ed.). Reader-response criticism: from formalism to post-structuralism. Baltimore: The Johns Hopkins University Press, 1986. p.70-100.

FREIRE, P. A importância do ato de ler. São Paulo: Cortez, 1995.

FREITAS, M.(Org.). Cibercultura e formação de professores. Belo Horizonte: Autêntica, 2009.

HESTER, R. From reading to the reading of literature. The moderne language journal. N.56, p.284-291, 1972.

ISER, W. The significance of fictionalizing. Anthropoetics: the eletronic journal of generative anthropology. n.2, 1998. Disponível em: <http://www.humnet.ucla.edu/humnet/anthropoetics> Acesso em: 17 out. 2000. 1996.

O ato da leitura: uma teoria do efeito estético. v.1. São Paulo: Ed. 34,

JACOBUS, L. (Org.) Teaching literature: a collection of essays on theory and practice. New Jersey: Prentice Hall, 1996.

KRAMER, S. Por entre as pedras: arma e sonho na escola. São Paulo: Ática, 1993.

LAJOLO, M. Literatura: leitores e leitura. São Paulo : Moderna, 2001.

LEAHY-DIOS, C. Língua e literatura: uma questão de educação? Campinas: Papirus, 2001.

LÉVY, P. Cibercultura. Rio de Janeiro: Ed. 34, 1999.

LOPES, S. R. A legitimação em Literatura. Lisboa: Cosmos, 1994.

MARTELETO, R. Análise de redes sociais - aplicação nos estudos de transferência da informação. Ci. Inf. 2001, vol. 30, n. 1, pp.71-81.

MATOS, M. V. Reflexões sobre leitura. Ler e escrever: ensaios. Lisboa, IN-CM, 1987.

MATTAR, J.; VALENTE, C. Second life e web 2.0 na educação: o potencial revolucionário das novas tecnologias. São Paulo: Novatec, 2007. 
MELO, J. M. Os meios de comunicação de massa e o hábito de leitura. In: BARZOTTO, V. H. (Org.). Estado de leitura. Campinas: Mercado de Letras. 1999.

PERRONE-MOISÉS, L. Altas Literaturas: escolha e valor na obra crítica de escritores modernos. São Paulo: Companhia das Letras, 1998, cap.5. p. 203-215.

PRENSKY, M. Digital natives, digital immigrants. The Horizon, v. 9, n. 5, 2001.

PRETTO, N.; ASSIS, A. Cultura digital e educação: redes já! In: PRETTO, N. ; SILVEIRA, S. (Orgs.) Além das redes de colaboração: internet, diversidade cultural e tecnologias do poder. Salvador: EDUFBA, 2008.

SILVA, Ezequiel. A leitura nos oceanos da internet (Coord.). São Paulo: Cortez, 2003.

Criticidade e leitura. Campinas: Mercado de letras, 1998.

SILVA, Ivanda. Literatura em sala de aula: da teoria à prática escolar. Recife: Programa de Pós-graduação em Letras. Coleção Teses, 2005.

SANTOS, E. Educação online para além da EAD: um fenômeno da Cibercultura. In: SILVA, M.; PESCE, L.; ZUIN, A. (org.s). Educação online: cenário, formação e questões didático-metodológicas. Rio de Janeiro: Wak Ed, 2010.

TOMAÉL, M. ALCARÁ, A.; CHIARA, I. Das redes sociais à inovação. Ci. Inf., Brasília, v. 34, n. 2, p. 93-104, maio/ago. 2005. 
Artigo recebido em: 01 de dezembro de 2014

Artigo aprovado em: 10 de abril de 2015

Sobre a autora:

Ivanda Maria Martins Silva é doutora em Letras (UFPE), professora adjunta da Universidade Federal Rural de Pernambuco (UFRPE), coordenadora do Curso de Licenciatura em Letras EAD/UFRPE. Atua no Programa PPGTEG/UFRPE- Pósgraduação em Tecnologia e Gestão em Educação a Distância na área de Práticas de Linguagem em EAD. É autora do livro Literatura em sala de aula: da teoria literária à prática escolar, publicação do Programa de Pós-graduação em Letras/UFPE (2005). 